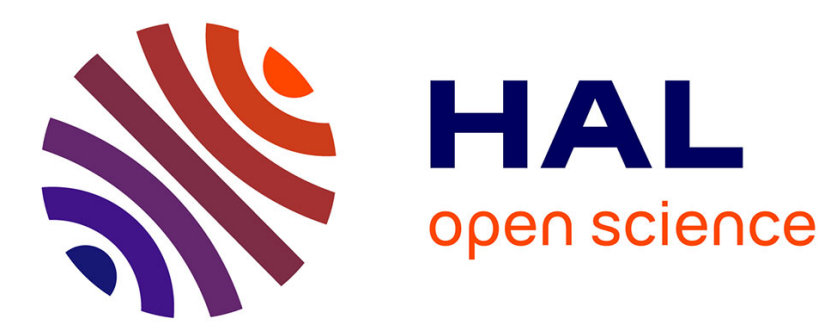

\title{
Characterisation of crystallinity at the interface of ultrasonically welded carbon fibre PPS joints
}

N. Koutras, Juliana Amirdine, N. Boyard, I. Fernandez Villegas, R. Benedictus

\section{To cite this version:}

N. Koutras, Juliana Amirdine, N. Boyard, I. Fernandez Villegas, R. Benedictus. Characterisation of crystallinity at the interface of ultrasonically welded carbon fibre PPS joints. Composites Part A: Applied Science and Manufacturing, 2019, 125, pp.105574. 10.1016/j.compositesa.2019.105574 . hal-02328711

\section{HAL Id: hal-02328711 \\ https://hal.science/hal-02328711}

Submitted on 26 Feb 2021

HAL is a multi-disciplinary open access archive for the deposit and dissemination of scientific research documents, whether they are published or not. The documents may come from teaching and research institutions in France or abroad, or from public or private research centers.
L'archive ouverte pluridisciplinaire HAL, est destinée au dépôt et à la diffusion de documents scientifiques de niveau recherche, publiés ou non, émanant des établissements d'enseignement et de recherche français ou étrangers, des laboratoires publics ou privés. 


\title{
Characterisation of Crystallinity at the Interface of Ultrasonically Welded Carbon Fibre PPS Joints
}

\author{
N. Koutras ${ }^{1}$, J. Amirdine ${ }^{2}$, N. Boyard ${ }^{2}$, I. Fernandez Villegas ${ }^{1}$, R. Benedictus ${ }^{1}$ \\ ${ }^{1}$ Aerospace Structures and Materials Department, Delft University of Technology, The Netherlands \\ 2Laboratoire de Thermique et Energie de Nantes, UMR 6607 CNRS / Université de Nantes, rue \\ Christian Pauc, CS 50609, F-44306 Nantes cedex 3, France
}

\begin{abstract}
The influence of ultrasonic welding on the crystallinity degree at the welding interface of carbon fibre reinforced polyphenylene sulphide (CF/PPS) joints was investigated. Two sets of welding force and vibration amplitude were used, $(1000 \mathrm{~N}, 86.2 \mu \mathrm{m})$ and $(300 \mathrm{~N}, 52.8 \mu \mathrm{m})$, representing short and long welding times, respectively. The evolution of temperature with time at the centre of the joint overlap was recorded using thermocouples while the crystallinity degree of PPS was measured using differential scanning calorimetry (DSC). The cooling rate dependency of crystallinity was determined through fast scanning calorimetry (FSC) measurements. It was found that high force and high amplitude resulted in faster cooling rates and predominantly amorphous PPS, while low force and low amplitude resulted in slower cooling rates and yielded PPS of moderate crystallinity. It is suggested that the capability of PPS to crystallise despite the very fast cooling rates could be attributed to straininduced crystallization during the welding process.
\end{abstract}

\section{Introduction}

Aerospace industry requirements of lightweight structures and cost-driven manufacturing have created the need for fast and cost-efficient joining processes. Welding of thermoplastic composites is a joining method with fast production cycles and minimal labour work. One of the most promising welding techniques is ultrasonic welding (USW), which is classified as a friction welding technique, converting high frequency (typically $20-40 \mathrm{kHz}$ ) and low amplitude mechanical vibrations into heat via friction. The produced vibrations are transverse to the weld interface and cause surface and intermolecular friction in the materials to be welded, which result in heat generation. In order to concentrate the heat 
generation between the adherends, energy directors (ED), which are made of the same polymer as the adherends' matrix, are placed at the welding interface [1] - [3]. The lower compressive stiffness of the energy directors compared to the composite adherends result in higher cyclic strains in the EDs during the welding process which, in turn, promote heat generation [2] - [4]. Ultrasonic welding is a very fast process, it does not require a foreign material in the interface and it produces excellent quality joints [1].

Most of the efforts so far, have been directed at investigating the heating mechanisms and the factors affecting the ultrasonic welding process and the weld strength. Benatar and Gutowski [5] studied the heating mechanism in ultrasonic welding of carbon fibre PEEK composites, dividing the mechanism into five steps, (i) mechanics and vibration, (ii) viscoelastic heating, (iii) heat transfer, (iv) flow and wetting, and (v) intermolecular diffusion. The heating and bonding mechanisms in ultrasonic welding of neat polystyrene were investigated and it was suggested that the most rapid heating occurred at the proximity of the welding interface [6]. Furthermore Levy et al. [7] showed that the heat initiated mainly due to friction dissipation between the energy director and the substrate in ultrasonic welding of CF/PEI composites. Amplitude of vibration and hold time were recognised as key factors affecting the weld performance [8] - [10], while higher force resulted in shorter welding times and lower welding energies [11]. Villegas demonstrated that power and displacement data can be related to weld strength and can be used for the in-situ monitoring of the welding process. Furthermore, increasing welding force and increasing vibration amplitude were found to significantly shorten the vibration times [1] [2].

The cycle times of the ultrasonic welding process are extremely fast (only a few seconds), hence, the cooling rates at the welding interface during ultrasonic welding are expected to be very high. Considering that the high-performance thermoplastics such as PEEK, PEKK and PPS are semicrystalline polymers, the speed of the ultrasonic welding process could have an effect on the properties of the polymer at the welding interface. In particular, when such semi-crystalline polymers are cooled very fast from the melt down to room temperature they can become predominantly amorphous or reach low levels of crystallinity degree, as it has already been reported [12] - [18]. Kenny and Maffezzoli [13] reported that quenching the PPS matrix system at cooling rates above 1.67 ${ }^{\circ} \mathrm{C} / \mathrm{s}$ can yield an amorphous structure, while in a later study [14] the same authors reported that PPS was quenched at a cooling rate of $6.67^{\circ} \mathrm{C} / \mathrm{s}$. Cebe and Chung [19] observed that cooling rates of 3.3 
${ }^{\circ} \mathrm{C} / \mathrm{s}$ did not yield an amorphous PPS since the polymer was still able to crystallise during cooling. Furthermore, Ferrara et al. [20] suggested a dual-mechanism for PPS melt crystallization which resulted in a minimum crystallinity of $8 \%$ independently of the processing conditions. In recent years, the crystallization of different resin systems at very fast cooling rates has been investigated by many researchers using fast scanning calorimetry [17] [18] [21] - [29]. A study on the crystallization of PPS using fast scanning calorimetry (FSC) revealed that PPS could not crystallise at cooling rates equal or higher than $20^{\circ} \mathrm{C} / \mathrm{s}$ [17]. Similarly, Furushima et al [28] investigated the crystallization and melting kinetics of PPS at very high scanning rates, and found that a $30{ }^{\circ} \mathrm{C} / \mathrm{s}$ cooling rate was sufficient to yield amorphous PPS. It is worth to mention that the cooling rates required to quench PPS were found to be lower in the older studies (at 80 s and 90s) compared to the ones reported nowadays. Possibly, the different grades of PPS available nowadays are capable of crystallizing faster. Furthermore, the limited capabilities of the thermal testing techniques used in the older studies did not allow for experiments to be conducted at temperatures close to the actual temperature of maximum crystallization rate. Regarding other relevant semi-crystalline polymers, cooling rates higher than 100 ${ }^{\circ} \mathrm{C} / \mathrm{s}$ resulted in a neat PEEK matrix with very low crystallinity levels, as shown in separate studies [16] [21] [30].

It has been well studied and documented that the semi-crystalline nature of thermoplastic matrix systems can influence properties such as stiffness, shear strength, fibre/matrix interfacial strength, fracture toughness and chemical resistance. Talbott et al. [16] studied the mechanical properties of PEEK and found that decreasing crystallinity led to a lower elastic modulus, lower tensile strength and lower shear strength for neat PEEK. Similar observations on the beneficial effect of crystallinity on the tensile properties of PPS and its composites have been made in past studies [17] [31]. Crystallinity has also been reported to have a positive influence on the interfacial shear strength of carbon fibre reinforced PPS and carbon fibre reinforced PEEK [14] [32]. On the contrary, a decrease in crystallinity has been demonstrated to cause an increase in Mode-I interlaminar fracture toughness of PEEK and PPS composites [16] [33] [34]. Along similar lines, in a previous study it was suggested that increasing crystallinity caused a reduction in fracture toughness of PEEK [35]. Furthermore, the fracture toughness of the weld interface of carbon fibre reinforced PPS tapes welded on carbon fabric PPS laminates, was shown to become substantially lower upon annealing [36]. In addition, it is well known that high-performance semi-crystalline thermoplastics possess excellent chemical resistance and low 
moisture absorption [31] [37] - [40], properties that are heavily influenced by the semi-crystalline structure of these polymers [38] [39] [41].

Hence, considering the very fast welding times of the ultrasonic welding process and given the influence of crystallinity on the final properties of polymers and fibre reinforced polymers, the investigation of the polymer state at the interface of ultrasonically welded thermoplastic composites joints is of significant importance. This article presents a characterisation of crystallinity at the interface of ultrasonically welded carbon fibre PPS joints, having two main objectives. First, to study the influence of the ultrasonic welding process parameters on the degree of crystallinity at the welding interface of CF/PPS joints and, second, to determine whether it is possible to obtain a semi-crystalline welding interface by appropriately modifying the process parameters. In order to determine the crystallinity degree and the average crystallite size of the matrix at the welding interface, differential scanning calorimetry (DSC) and Wide-Angle X-ray diffraction (WAXD) measurements on energy director films removed from the welding interface after the welding process, were performed. The temperature profile at the centre of the joint overlap was measured, using thermocouples embedded in energy directors. The dependence of the crystallinity degree on the cooling rate, as well as the critical cooling rate at which the matrix crystallization is suppressed, were determined using fast scanning calorimetry. The conventional DSC technique could not be used to study the thermal transitions of polymers at very high heating and cooling rates (applicable to the ultrasonic welding process) due to its limited capabilities [27] [29], therefore the FSC technique was employed.

\section{Experimental Procedure}

\section{$2.1 \quad$ Materials}

The material used in this study was Cetex® woven (five harness satin) carbon fibre reinforced polyphenylene sulphide composite (CF/PPS) supplied by Ten Cate Advanced Composites, The Netherlands. Laminates measuring $580 \mathrm{~mm} \times 580 \mathrm{~mm}$ were built from six powder-impregnated CF/PPS layers with a stacking sequence of $\left[\left(0^{\circ} / 90^{\circ}\right)_{3}\right]$ s, with a nominal $50 \%$ fibre volume content. The laminates were consolidated using a hot platen press at $320{ }^{\circ} \mathrm{C}$ and $1 \mathrm{MPa}$ pressure for $20 \mathrm{~min}$ and subsequently cooled down at a cooling rate of $15{ }^{\circ} \mathrm{C} / \mathrm{min}$. The stainless steel moulds used in the press consolidation process were first cleaned with acetone, then degreased with PFQD degreasing agent 
(from Socomore) and finally coated with Marbocote 227CEE release agent. The final thickness of the consolidated laminates was $1.9 \mathrm{~mm}$. Welding adherends and test specimens were cut from the consolidated laminates using a water-cooled diamond blade. Flat ED films were consolidated by placing three $0.08 \mathrm{~mm}$-thick amorphous PPS films between two stainless steel moulds in a hot platen press at $270{ }^{\circ} \mathrm{C}$ and $1 \mathrm{MPa}$ pressure for $20 \mathrm{~min}$. The ED films were cooled down at $15^{\circ} \mathrm{C} / \mathrm{min}$ and had a final thickness of $0.24 \mathrm{~mm}$.

\section{$2.2 \quad$ Ultrasonic Welding}

All the joints in this study were manufactured using a $20 \mathrm{kHz}$ Rinco 3000 microprocessor-controlled ultrasonic welder with maximum power output of 3000 W (Rinco Ultrasonics, Romanshorn, Switzerland) in a single-lap configuration. Figure 1 depicts the ultrasonic welder and the welding jig, which consists of a clamp for the bottom adherend, a clamp for the top adherend, and a sliding platform which allows vertical movement of the top adherend. The welding jig also prevented shifting of the adherends during the welding process. The diameter of the cylindrical titanium sonotrode was $40 \mathrm{~mm}$. The adherends and the energy director were always degreased prior to welding using a degreasing agent (PFQD). The energy director was fixed on the bottom adherend prior to the welding process using an adhesive tape.

The ultrasonic welding process consists of two phases, the vibration phase during which heat is generated via friction and the matrix only starts to melt and flow, and the solidification phase during which the weld is cooled down under constant pressure, achieving consolidation. The USW machine provides output curves of dissipated power and vertical displacement with respect to vibration time, after each weld. It is possible to control the ultrasonic welding process through the vibration time, the dissipated energy or the vertical displacement of the sonotrode. However, it is known that controlling the process through the vertical displacement (called "travel" hereafter) of the sonotrode, can produce consistently high-strength welds [1]. Therefore, the process in this study was "displacementcontrolled", i.e. the vibration phase was terminated after the sonotrode travelled a certain distance (called "optimum travel"). The procedure that was followed in order to determine the optimum travel values has been described in previous work [1]. The optimum travel values used per experiment are provided in the sections 2.3 and 2.4.2. As it was previously mentioned in the introduction section, 
increasing the welding force as well as the vibration amplitude result in shorter vibration times which could, possibly, influence the heat generation during the welding process and, evidently, have an effect on the cooling rates that PPS experiences. Hence, the influence of the ultrasonic welding process on PPS crystallinity at the welding interface was investigated with respect to the welding force and the vibration amplitude.

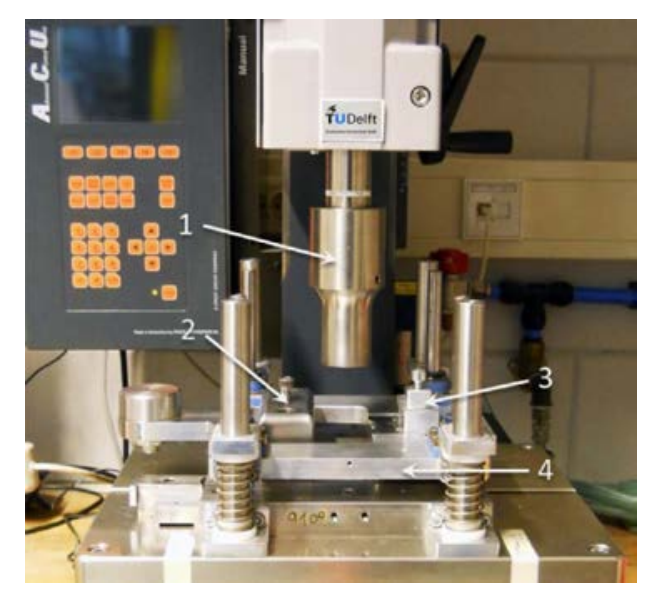

Figure 1. Utrasonic welder and welding jig. (1) sonotrode, (2) sliding support for top clamp, (3) top clamp, (4) bottom clamp.

Two different sets of force and peak-to-peak vibration amplitude, $(1000 \mathrm{~N}, 86.2 \mu \mathrm{m})$ and $(300 \mathrm{~N}, 51.8$ $\mu \mathrm{m})$, were used to study the effect of the process parameters on crystallinity of PPS at the welding interface. The first set represents the fast process (vibration times around $400 \mathrm{~ms}$ ) while the second set represents the slower process (vibration times around $1500 \mathrm{~ms}$ ). The solidification phase was characterised by the solidification time which was $4000 \mathrm{~ms}$, and the solidification force which remained constant, and equal to the welding force, for all the welded joints produced in this study.

\subsection{Temperature Measurements}

The temperature at the centre of the overlap was measured in order to obtain the temperature profile of the ultrasonic welding process during the vibration phase and the solidification phase. Embedding a thermocouple inside the energy director was proven to be the most effective method to measure the temperature at the welding interface. Machining a groove on the adherend surface and then inserting a thermocouple inside the groove was also considered, however, the edges of the groove would act as heat concentrators and interfere with the welding process. In addition, a thermal camera could not be used because the weldline view was blocked from the welding set-up itself. 
K-type thermocouples with a diameter of $0.1 \mathrm{~mm}$ were placed between four films of amorphous PPS. Prior to press consolidation, the thermocouples were manually fixed on the PPS films using a Rinco handheld ultrasonic welder. Figure 2 illustrates a schematic representation of manufacturing of EDs with embedded thermocouples. Two stainless steel moulds were used as the bottom and top moulds (cleaned following the procedure described in 2.1). A silicon layer of $1.95 \mathrm{~mm}$ thickness was placed in between the top mould and the PPS films stack for achieving a more uniform pressure distribution (the presence of the thermocouples caused a non-uniform pressure distribution). The silicon layer was sandwiched between two $25 \mu$ m-thick polyimide (Kapton, from Dupont) films (called "Kapton films" hereafter), to prevent contact with the EDs which, in turn, would cause contamination of the product. The stack was consolidated in a hot platen press following the same cycle used for the consolidation of EDs (described in section 2.1), having a final thickness of $0.32 \mathrm{~mm}$, instead of $0.24 \mathrm{~mm}$, to ensure that the thermocouples were located in the centre of the energy directors. It is worth noting here, that by using a thicker ED for the temperature measurements $(0.32 \mathrm{~mm}$ instead of $0.24 \mathrm{~mm})$ slightly lower cyclic strains would occur as it was shown by Palardy and Villegas [3].

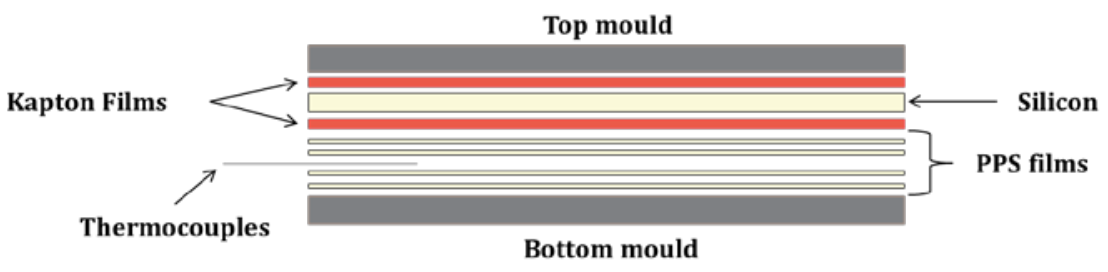

Figure 2. Schematic of manufacturing of energy directors with embedded thermocouples. Dimensions are not to scale.

The ED with the embedded thermocouple (ETC) was fixed on the bottom substrate using an adhesive tape, ensuring that the thermocouple tip was located at the centre of the overlap (Figure 3). The optimum travel for both sets of parameters was $0.22 \mathrm{~mm}$. The temperature was recorded during ultrasonic welding using a Thermocouple Data Logger, TC-08, from Pico Technology, at a frequency of $10 \mathrm{~Hz}$. It must be noted, that the sampling rate (1 measurement recorded per $100 \mathrm{~ms}$ ) in conjunction with the very rapid cycle times of USW (typically 4-5 s) might have limited the precision of the measurements. The specimen series welded using a force of $1000 \mathrm{~N}$ and a peak-to-peak vibration amplitude of $86.2 \mu \mathrm{m}$ are denoted by ETC_F ("F" stands for fast process), while the specimen series welded using a force of $300 \mathrm{~N}$ and peak-to-peak vibration amplitude of $51.8 \mu \mathrm{m}$ are denoted by 
ETC_S ("S" stands for slow process). In total, two ETC_F specimens, three ETC_S specimens, and two Kapton_ETC_S specimens were tested. Table 1 presents the welding conditions and the number of measurements per series.

Table 1. Welding conditions and number of measurements per series.

\begin{tabular}{lcccc}
\hline $\begin{array}{c}\text { Specimen } \\
\text { Series }\end{array}$ & $\begin{array}{c}\text { Number of } \\
\text { measurements }\end{array}$ & $\begin{array}{c}\text { Welding } \\
\text { Force }(\mathrm{N})\end{array}$ & $\begin{array}{c}\text { Vibration } \\
\text { Amplitude }(\boldsymbol{\mu m})\end{array}$ & $\begin{array}{c}\text { Travel } \\
(\mathbf{m m})\end{array}$ \\
\hline ETC_F & 2 & 1000 & 86.2 & 0.22 \\
ETC_S & 3 & 300 & 51.8 & 0.22 \\
Kapton_ETC_S & 2 & 300 & 51.8 & 0.22 \\
\hline
\end{tabular}

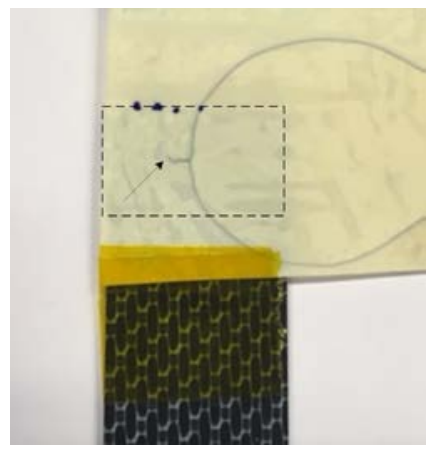

Figure 3. ED with embedded thermocouple prior to ultrasonic welding, positioned in such way to measure the temperature at the centre of the overlap (highlighted area). The arrow in the picture points at the tip of the thermocouple (location of the temperature measurements).

In order to calculate the cooling rates, the temperature at which the crystallization rate is maximum needs to be known. The maximum crystallization rate of a semi-crystalline polymer occurs at a temperature approximately around the midpoint of the glass transition temperature ( $\mathrm{Tg}$ ) and the equilibrium melting temperature [31] [42] [43]. Close to the $\mathrm{Tg}$, the molecular movement is sluggish while close to the melting temperature the crystal nucleation rate and the growth rate are very low, hence, the rate of crystallization is very slow close to both temperatures; at the midpoint between the two temperatures, the balance between the chain mobility and the nucleation rate results in the fastest crystallization rate. Chung and Cebe [44] reported that the fastest crystallization rate for PPS occurred between $170{ }^{\circ} \mathrm{C}$ and $190{ }^{\circ} \mathrm{C}$, while Furushima et al. [28] reported the fastest rate at $160{ }^{\circ} \mathrm{C}$, thus, we assumed that in this study the maximum crystallization rate of PPS occurred between $160{ }^{\circ} \mathrm{C}$ and 190 ${ }^{\circ} \mathrm{C}$. 


\section{$2.4 \quad$ Crystallinity Assessment}

\subsubsection{Flash DSC}

The FSC experiments were performed using a Mettler Flash DSC 1 calorimeter, which is a chip-based fast scanning device with power compensation. The chip sensor had an active area of $500 \mu \mathrm{m}$ and the thickness of the membrane was approximately $2 \mu \mathrm{m}$. The maximum heating and cooling rates can reach up to $20000{ }^{\circ} \mathrm{C} / \mathrm{s}$ and $5000{ }^{\circ} \mathrm{C} / \mathrm{s}$, respectively. The specimens were prepared from a piece of ED under a microscope and placed in the centre of the chip sensor as illustrated in Figure 4. The specimen was purged with dry nitrogen gas at a flow rate of $10 \mathrm{~mL} / \mathrm{min}$. A good thermal contact between the specimen and the sensor was achieved by, first, melting the specimen on the sensor by heating it up to $320^{\circ} \mathrm{C}$ at a $10^{\circ} \mathrm{C} / \mathrm{s}$ heating rate and, subsequently, consolidating the specimen on the sensor by cooling it down to room temperature at $1000{ }^{\circ} \mathrm{C} / \mathrm{s}$. As a result, the preparation procedure does not allow measurements of an "as-received" specimen using the FSC technique. Hence, after the first heating/cooling cycle that was required to melt and consolidate the specimen on the sensor, a second cycle with very slow cooling equal to $0.16{ }^{\circ} \mathrm{C} / \mathrm{s}$ was performed, in order to obtain a semicrystalline structure of PPS. The effect of cooling rate on the crystallinity of PPS was investigated by selecting eight cooling rates, between 0.16 and $50{ }^{\circ} \mathrm{C} / \mathrm{s}$ (Table 2). The rate of the heating scans was $1000{ }^{\circ} \mathrm{C} / \mathrm{s}$ in order to prevent reorganisation of crystals which can occur upon heating [26] [27]. The mass of the specimens (per sensor) ranged between $250-500 \mathrm{ng}$. Such low masses cannot be weighed using common balances (which normally have a readability of $0.01 \mathrm{mg}$ ), thus, an alternative approach has been adopted in literature. In particular, the heat capacity or the melting enthalpy can be used to estimate the specimen mass [18] [21] [27]. In this study, the melting enthalpy was used to estimate the specimen mass, $m_{F D s c}$, using the following equation:

$\mathbf{m}_{\mathrm{FDSC}}=\frac{\Delta \mathrm{H}_{\mathrm{FDSC}}}{\Delta \mathrm{H}_{\mathrm{DSC}}} * \mathbf{m}_{\mathrm{DSC}}$

Where:

- $\Delta \mathrm{H}_{\mathrm{FDSC}}$, (in $\mathrm{J}$ ) is the measured melting enthalpy determined from the melting peak of PPS previously crystallized at $0.16^{\circ} \mathrm{C} / \mathrm{s}$, using FSC. 
- $\Delta \mathrm{H}_{\mathrm{DSC}}$ (in $\mathrm{J}$ ) is the measured melting enthalpy determined from the melting peak of PPS previously crystallized at $0.16{ }^{\circ} \mathrm{C} / \mathrm{s}$, using Standard DSC.

- $\quad \mathrm{m}_{\mathrm{DSC}}$ is the mass of the specimen used in the standard DSC.

The degree of crystallinity, $\mathrm{X}_{\mathrm{c}}$, was calculated using the following equation:

$X_{c}=\frac{\Delta H_{m}}{\Delta H_{f}^{o}} * 100(\%)$

Where $\Delta \mathrm{H}_{\mathrm{m}}$ is the measured specific melting enthalpy in $\mathrm{J} / \mathrm{g}$ and $\Delta \mathrm{H}_{\mathrm{f}}^{0}$ is the specific melting enthalpy of an ideal crystal $\left(\Delta \mathrm{H}_{\mathrm{f}}^{\mathrm{o}}=112 \mathrm{~J} / \mathrm{g}[45]\right)$.

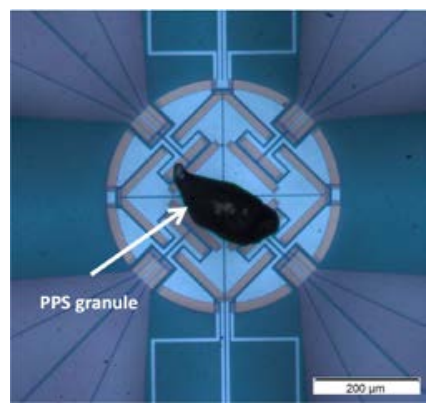

Figure 4. Example of a PPS granule placed at the centre of the chip sensor.

Table 2. Number of FSC measurements per cooling rate.

\begin{tabular}{|c|c|c|c|c|c|c|c|c|}
\hline Cooling Rate ( $\left.{ }^{\circ} \mathbf{C} / \mathbf{s}\right)$ & 0.16 & 0.33 & 1 & 1.6 & 5 & 10 & 20 & 50 \\
\hline Number of Measurements & 4 & 2 & 1 & 1 & 3 & 4 & 2 & 2 \\
\hline
\end{tabular}

\subsubsection{Standard DSC and WAXD Analysis}

Removing material from the welding interface of a consolidated welded joint is necessary to perform DSC or WAXD experiments, however, it requires meticulous attention in order to prevent material from the welding interface from being mixed with material from the adjacent plies (i.e. $1^{\text {st }}$ ply of the adherend). For example, PPS in powder form could be obtained by grinding the cross-section of the joint but it is impossible to determine whether the powder originated from the welding interface or from the resin rich areas of the adherends. Therefore, an alternative and quite simple method was used. Prior to welding, two $25 \mu \mathrm{m}$-thick Kapton films were fixed with tape one to each adherend and, subsequently, the ED was sandwiched between the Kapton films and fixed with an adhesive tape as well (Figure 5). The ultrasonic welding process was carried out as described in section 2.2 and the ED 
was easily removed from the welding interface after the completion of the welding process, due to the Kapton films. The optimum travel values for the two sets of parameters, $(1000 \mathrm{~N}, 86.2 \mu \mathrm{m})$ and $(300$ $\mathrm{N}, 51.8 \mu \mathrm{m}$ ), were $0.15 \mathrm{~mm}$ and $0.13 \mathrm{~mm}$, respectively. The ED films removed after welding with high force and high vibration amplitude are denoted by ED_F and the films removed after welding with low force and low vibration amplitude are denoted by ED_S. The details of the preparation conditions of the ED films removed from the welding interface (called "removed EDs" hereafter) are summarised in Table 3. In addition, in order to study the effect of the initial state of PPS (amorphous or semicrystalline) on the final crystallinity of PPS, EDs made of amorphous PPS were prepared by cutting three amorphous PPS films (0.08 mm thick each) into sections of $30 \mathrm{~mm} \times 30 \mathrm{~mm}$ and stacking them together by spot welding the four corners using a Rinco handheld ultrasonic welder. The final thickness of the amorphous EDs was $0.24 \mathrm{~mm}$. The amorphous ED films were placed between the two adherends and welded using the $20 \mathrm{kHz}$ Rinco 3000 ultrasonic welder (Figure 1). After the completion of ultrasonic welding, the EDs were removed from the welding interface following the same procedure described in this section (Figure 5). If there is any effect of the initial state of PPS on its crystallinity degree at the welding interface, the effect would be more pronounced and easier to study at slower cooling rates which were expected to be obtained by using low welding force and low vibration amplitude. Hence, the amorphous EDs were welded using a welding force of $300 \mathrm{~N}$ and a vibration amplitude of $51.8 \mu \mathrm{m}$, and are denoted by AMR_ED_S. It is important to note though, that the removed ED films were not fully representative of an ED of a consolidated welded joint produced without the interference of Kapton films. The presence of Kapton films might have an influence on the heat generation and heat transfer as the ED is in contact with the Kapton films and not with the composite adherends. On these grounds, energy directors with embedded thermocouples were placed between two Kapton films following the corresponding procedures described in sections 2.3 and 2.4.2 regarding temperature measurements and the use of Kapton films. Two specimens produced using low welding force and low vibration amplitude were tested, denoted by Kapton_ETC_S. The potential implications of using Kapton films are addressed in the discussion section. 


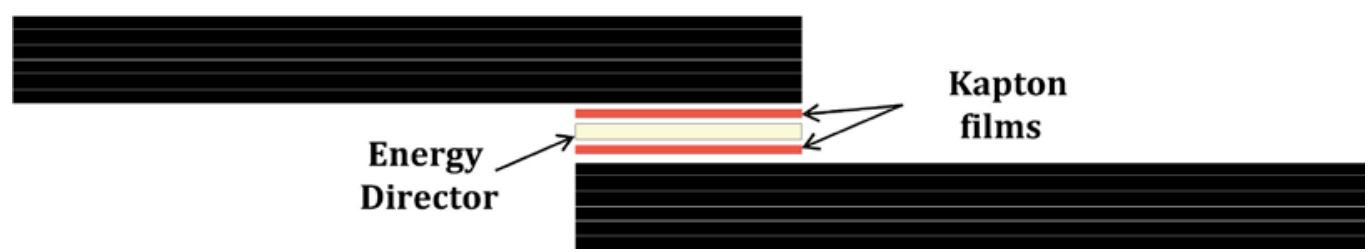

Figure 5. Schematic of specimen prepared for removing the energy directors from the welding interface in order to perform direct crystallinity measurements. Dimensions are not to scale.

Table 3. Preparation conditions of removed EDs.

\begin{tabular}{lcccc}
\hline $\begin{array}{c}\text { Specimen } \\
\text { Series }\end{array}$ & $\begin{array}{c}\text { Welding } \\
\text { Force }(\mathbf{N})\end{array}$ & $\begin{array}{c}\text { Vibration } \\
\text { Amplitude }(\boldsymbol{\mu m})\end{array}$ & $\begin{array}{c}\text { Travel } \\
(\mathbf{m m})\end{array}$ & $\begin{array}{c}\text { ED state prior to } \\
\text { welding }\end{array}$ \\
\hline ED_F & 1000 & 86.2 & 0.15 & Semi-crystalline \\
ED_S & 300 & 51.8 & 0.13 & Semi-crystalline \\
AMR_ED_S & 300 & 51.8 & 0.13 & Amorphous \\
\hline
\end{tabular}

Standard DSC measurements on ED films in their initial state (after press consolidation and prior to ultrasonic welding, hereafter called "ED_Ref") and on the specimens presented in Table 3 were carried out in a Sapphire DSC from Perkin Elmer. The melting peak temperature and heat of fusion were calibrated prior to the experiments following indium standards. Three measurements per series were performed: the specimens were heated from $25{ }^{\circ} \mathrm{C}$ to $310{ }^{\circ} \mathrm{C}$ at $10{ }^{\circ} \mathrm{C} / \mathrm{min}$, in a nitrogen atmosphere, and the degree of crystallinity was determined from the heating run and calculated using the following equation:

$X_{c}=\frac{\Delta H_{m}-\Delta H_{c}}{\Delta H_{f}^{o}} * 100(\%)$

Where $\Delta \mathrm{H}_{\mathrm{m}}$ is the measured specific melting enthalpy in $\mathrm{J} / \mathrm{g}, \Delta \mathrm{H}_{\mathrm{c}}$ is the specific energy associated with the cold crystallization peak in $\mathrm{J} / \mathrm{g}$, and $\Delta \mathrm{H}_{\mathrm{f}}^{\mathrm{o}}$ is the specific melting enthalpy of an ideal crystal $\left(\Delta \mathrm{H}_{\mathrm{f}}^{\mathrm{o}}=112 \mathrm{~J} / \mathrm{g}[45]\right)$.

Valuable information about the state of PPS can also be obtained via measuring the change in the specific heat capacity $\left(\Delta \mathrm{C}_{\mathrm{p}}\right)$ in the glass transition region: a higher amount of the specific heat capacity could mean a higher amorphous content. $\Delta \mathrm{C}_{\mathrm{p}}$ was measured using the Perkin Elmer software.

An X-ray powder diffractometer from Bruker was used for the WAXD measurements (one per series) on amorphous PPS (80 $\mu \mathrm{m}$ thick), ED_Ref $(250 \mu \mathrm{m}$ thick $)$, ED_F $(70 \mu \mathrm{m}$ thick $)$ and ED_S $(90 \mu \mathrm{m}$ thick). The samples were in the shape of films. There was no WAXD measurement on AMR_ED_S 
due to lack of samples at the time the WAXD tests were performed. The diffractograms were [46] [47] obtained using a Cobalt radiation source. The average crystallite size, D, was estimated using the Scherrer equation [46] [47]:

$D=K \lambda /(\beta \cos \theta)(\AA)$

Where $\mathrm{K}$ is a shape factor (approximately $0.9[46]-[48], \lambda$ is the X-ray wavelength $(1.789 \AA$ for Cobalt), $\beta$ is the full-width at the half maximum intensity of the diffraction peak and $\theta$ is the Bragg angle. It is noted, that although WAXD is not the most accurate method to measure crystal size (Small-Angle X-Ray Scattering would measure with a higher precision [49], the results shown in this paper can still be considered reliable and acceptable because they still have the correct order of magnitude and they are mainly used for comparison purposes.

\section{Results}

\subsection{Temperature measurements}

Figure 6 shows the temperature evolution during ultrasonic welding for one specimen per series. As it can be seen the time-temperature relationship was non-linear, therefore it was considered inaccurate to calculate and provide a global cooling rate. Instead, the temperature region between the equilibrium melting temperature of PPS (between 298-330 ${ }^{\circ} \mathrm{C}$ [31]) and $160{ }^{\circ} \mathrm{C}$ was divided into smaller temperature regions, in which the time-temperature relationship was assumed quasi-linear, allowing the cooling rates to be calculated. For all series, the cooling rates decreased continuously with increasing time, and the lowest cooling rate was calculated between $190{ }^{\circ} \mathrm{C}$ and $160{ }^{\circ} \mathrm{C}$; in this temperature region, the cooling rate for ETC_F was $41.0 \pm 8.4{ }^{\circ} \mathrm{C} / \mathrm{s}$, for ETC_S was $16.9 \pm 5.9{ }^{\circ} \mathrm{C} / \mathrm{s}$ and for Kapton_ETC_S it was $10.9 \pm 2.1^{\circ} \mathrm{C} / \mathrm{s}$. Therefore, although a global cooling rate could not be used due to the non-linearity between time and temperature, it can be said that the rates at which PPS was cooling down from the equilibrium melting temperature to $190{ }^{\circ} \mathrm{C}$, were higher than the abovementioned cooling rates. Between $160{ }^{\circ} \mathrm{C}$ and $120^{\circ} \mathrm{C}$ the cooling rates decreased even further, reaching $3.9 \pm 0.1{ }^{\circ} \mathrm{C} / \mathrm{s}$ and $3.5 \pm 1.0^{\circ} \mathrm{C} / \mathrm{s}$ for ETC_S and Kapton_ETC_S, respectively. The cooling rate of ETC F on the other hand was much faster, being measured around $19 \pm 3.6{ }^{\circ} \mathrm{C} / \mathrm{s}$. An 
additional point to be made from these calculations is the relatively large experimental errors in most of the cooling rates which is addressed in the discussion section.

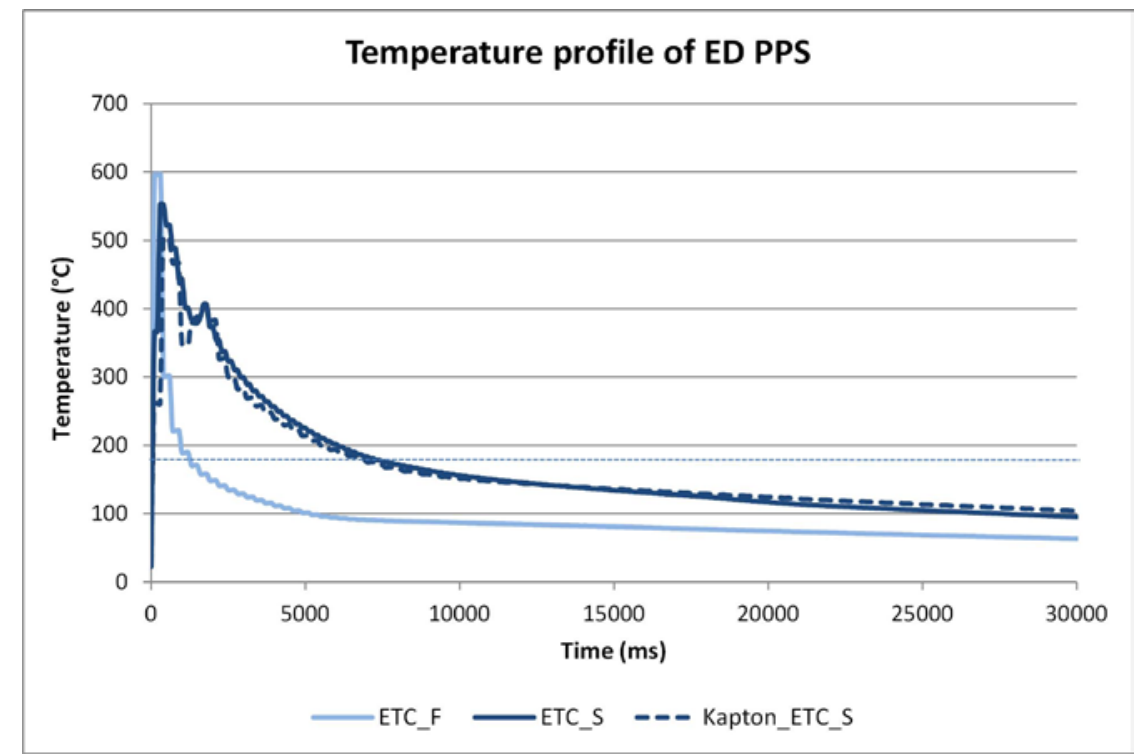

Figure 6. Temperature evolution during ultrasonic welding of ETC_F, ETC_S and Kapton_ETC_S. Only one specimen per series is illustrated for clarity purposes.

\subsection{FSC measurements}

Figure 7 shows FSC heating curves for PPS previously subjected at different cooling rates (ranging from $0.16{ }^{\circ} \mathrm{C} / \mathrm{s}$ to $50{ }^{\circ} \mathrm{C} / \mathrm{s}$ ). In this figure, all the measurements were carried out using the same chip sensor. Four main observations regarding the melting peaks can be made from this graph. Increasing cooling rates seems (i) to result in smaller melting peaks, (ii) to shift the melting peaks to lower temperatures and (iii) to broaden the melting peaks, which were characterised by a "shoulder" shifting to lower temperatures with increasing cooling rates (above $0.33{ }^{\circ} \mathrm{C} / \mathrm{s}$ ). Finally, (iv) PPS previously cooled at $20^{\circ} \mathrm{C} / \mathrm{s}$ showed a very weak signal, exhibiting an almost negligible melting peak. Further increase of the cooling rate $\left(\right.$ at $\left.50^{\circ} \mathrm{C} / \mathrm{s}\right)$ resulted in no melting peak indicating a completely amorphous structure. In addition, all heating curves exhibited a smaller endothermic signal at lower temperatures, very close to the glass transition; this phenomenon could be attributed to the enthalpy relaxation occurring during the previous cooling and/or heating curve, as it was suggested by Furushima et al. [28]. This smaller endothermic peak shifted to lower temperatures with increases in the preceding cooling rates. 


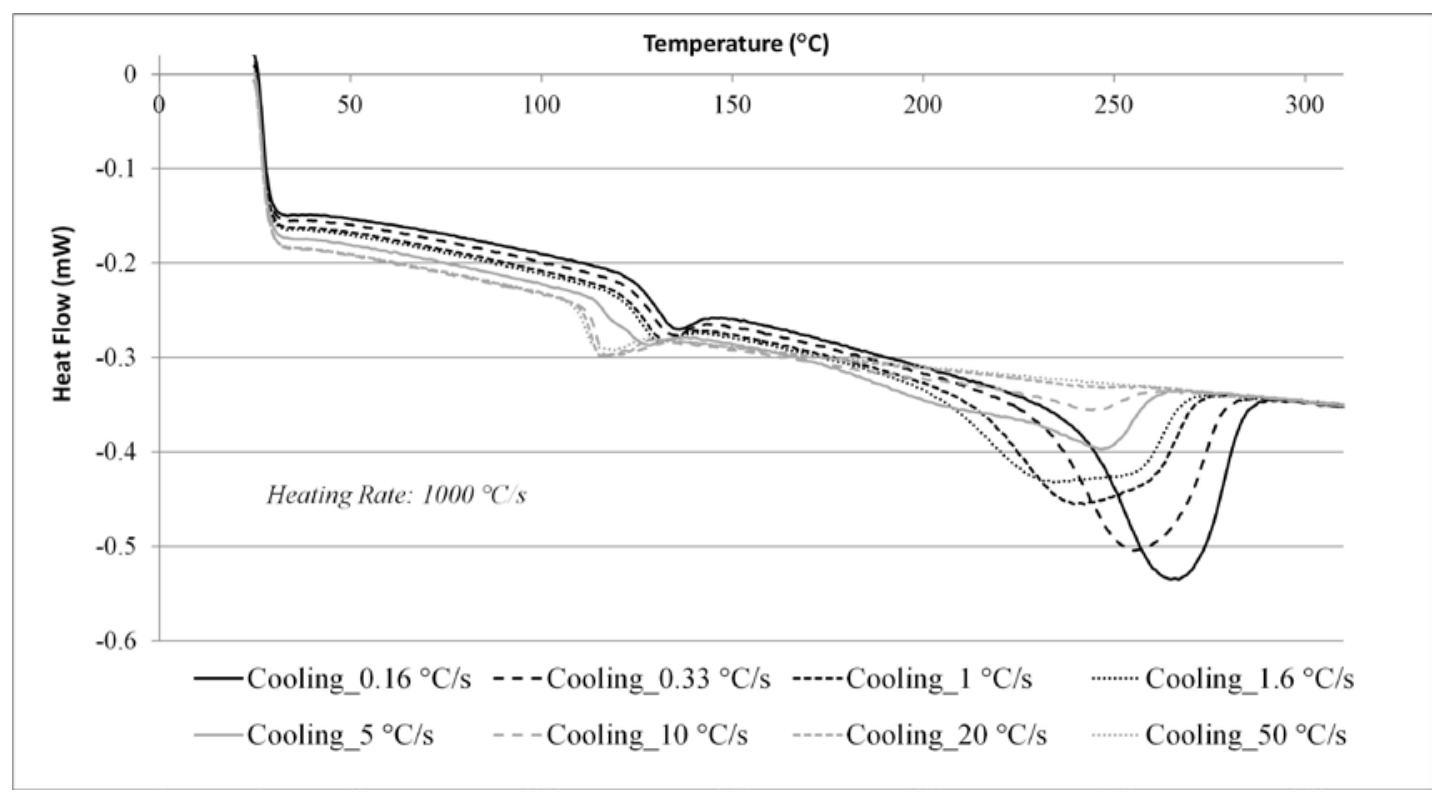

Figure 7. FSC heating curves of PPS $\left(1000^{\circ} \mathrm{C} / \mathrm{s}\right)$ performed after cooling from $320^{\circ} \mathrm{C}$ to RT at eight different cooling rates using the same chip sensor.

The dependency of the crystallinity degree on cooling rate is illustrated in Figure 8. As it was already indicated by the smaller melting peaks in Figure 7 , higher cooling rates resulted in lower crystallinity values.

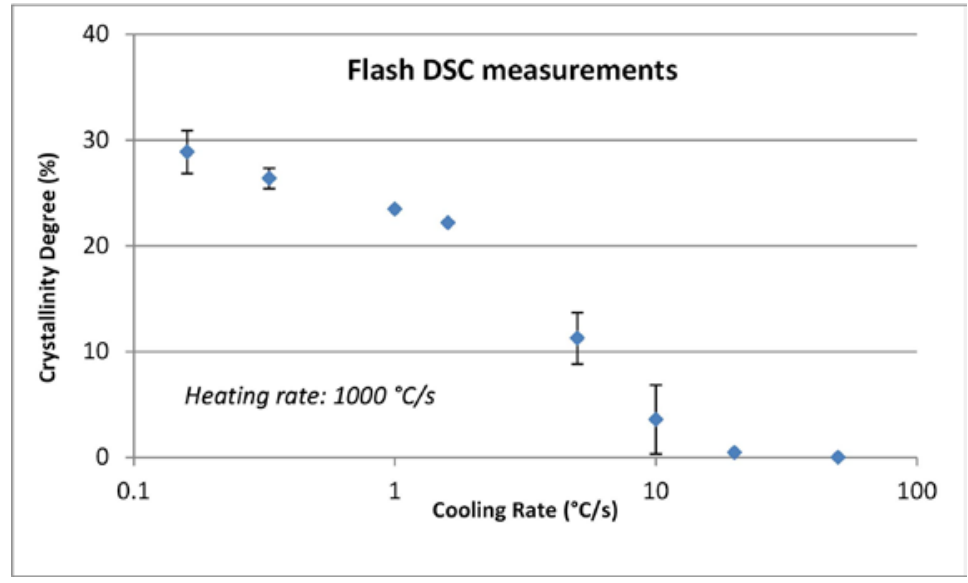

Figure 8. FSC measurements performed on neat PPS showing the dependence of crystallinity on cooling rate, and the critical cooling rate at which crystallization is suppressed $\left(20^{\circ} \mathrm{C} / \mathrm{s}\right)$.

The highest degree of crystallinity, $28.9 \%$, was measured for the lowest cooling rate, $0.16{ }^{\circ} \mathrm{C} / \mathrm{s}$. The reduction of crystallinity degree was relatively gradual up to $1.6^{\circ} \mathrm{C} / \mathrm{s}$, where the degree of crystallinity was $22.2 \%$. A further increase in cooling rate, though, caused a substantial decrease in crystallinity: at a cooling rate of $5{ }^{\circ} \mathrm{C} / \mathrm{s}$ the crystallinity degree was $11.3 \%$ while at a cooling rate of $10{ }^{\circ} \mathrm{C} / \mathrm{s}$ the 
degree of crystallinity was only 3.6\%. However, it must be noted that the standard deviation for the last two values was quite large, especially for the latter. Finally, the critical cooling rate at which crystallization was suppressed was $20^{\circ} \mathrm{C} / \mathrm{s}$. Such cooling rate yielded almost amorphous PPS, exhibiting a crystallinity degree of only $0.5 \%$.

\subsection{DSC and WAXD analysis of removed EDs}

Figure 9 shows two energy directors that were removed from the welding interface after welding under different conditions, where clear differences in terms of transparency can be observed. A welding force of $1000 \mathrm{~N}$ and a vibration amplitude of $86.2 \mu \mathrm{m}$ produced a predominantly transparent film, with some small opaque areas (Figure 9). Contrarily, a welding force of $300 \mathrm{~N}$ and a vibration amplitude of 51.8 $\mu \mathrm{m}$ produced an opaque film with some randomly distributed small transparent areas (Figure 9).
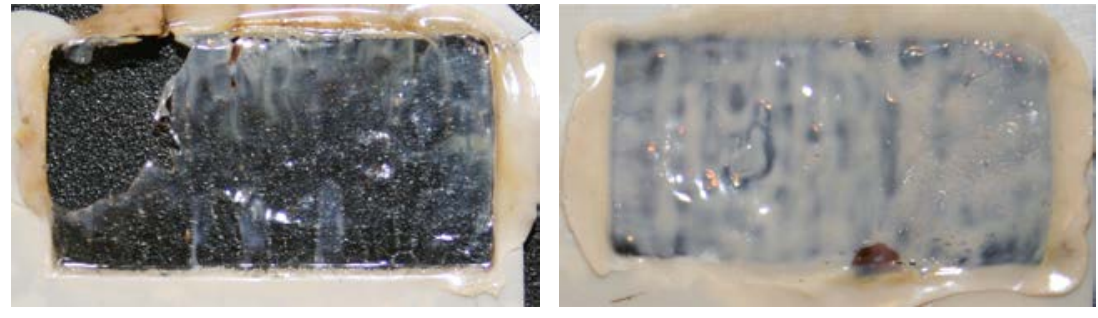

Figure 9. Energy directors removed after welding at 1000 N, $86.2 \mu \mathrm{m}$ (left) and at $300 \mathrm{~N}, 51.8 \mu \mathrm{m}$ (right). High force and high vibration amplitude produced a predominantly transparent film, while low force and low vibration amplitude produced an opaque film. A black background was used in order to facilitate observation of the films.

Figure 10 illustrates heating curves of standard DSC measurements carried out on removed EDs and on ED_Ref. Three measurements per ED film were performed but only one measurement per ED film is shown in Figure 10 for clarity purposes. As the DSC graph demonstrates, only the ED_Ref specimen did not exhibit an exothermal peak while the other three specimens exhibited an exothermal peak around $128{ }^{\circ} \mathrm{C}$, due to cold crystallization, with the ED_F specimen showing the most pronounced one. Cold crystallization occurs above the glass transition temperature during heating from the glassy state; it was an indication of a partial crystallization during the previous specimen cooling due to a too fast cooling rate with respect to crystallization kinetics. The enthalpy associated to the cold crystallization is related to the PPS fraction which did not have time to crystallize during cooling prior to the DSC heating scan. In addition, the change of the specific heat capacity $\left(\Delta C_{p}\right)$ at the glass transition (around $90^{\circ} \mathrm{C}$ ) was larger for ED_F $\left(0.17 \pm 0.01 \mathrm{~J} /\left(\mathrm{g}^{* \circ} \mathrm{C}\right)\right.$ ) compared to ED_S $(0.1$ 
$\left.\mathrm{J} /\left(\mathrm{g}^{* \circ} \mathrm{C}\right)\right)$, indicating that ED_F specimens had a larger amorphous phase fraction compared to ED_S. It is noted that for ED_F, the $\Delta C_{p}$ value was an average of three measurements while for ED_S the specific heat capacity "step" was detectable in only one measurement. It was not possible to detect the corresponding specific heat capacity "steps" in the other ED_S and AMR_ED_S specimens, despite the use of higher heating rates $\left(20^{\circ} \mathrm{C} / \mathrm{min}\right)$ or the $1^{\text {st }}$ derivative of the heat flow.

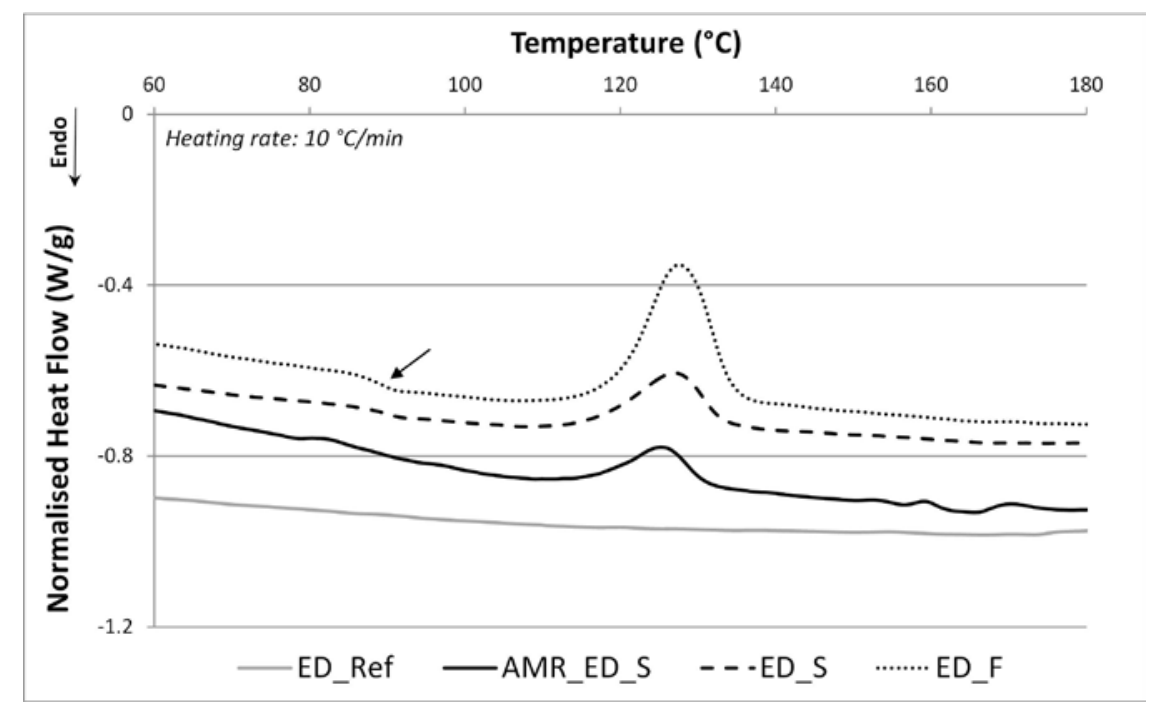

Figure 10. Standard DSC measurements on energy director prior to ultrasonic welding (reference, i.e. after press consolidation and before welding) and on energy directors removed from the welding interface under different welding conditions. The graph focuses on the cold crystallization peaks of the four specimens and the glass transition region of PPS. The arrow pointing at the ED_F curve, indicates the $\triangle \mathrm{Cp}$ "step" at the glass transition. The curves are vertically shifted for better clarity.

Figure 11 shows the same heating curves as Figure 10 but focusing only on the melting peaks of the four specimens (illustrating only the temperature range between $180{ }^{\circ} \mathrm{C}$ and $300{ }^{\circ} \mathrm{C}$ ). Only one endotherm peak corresponding to the melting of PPS crystals was observed per specimen. In addition, the melting peak temperature was found to be approximately $280^{\circ} \mathrm{C}\left( \pm 1^{\circ} \mathrm{C}\right)$ in all series. The average crystallinity degree values were calculated using equation (3) and are outlined in Figure 12. The crystallinity degree of ED_Ref was $26 \%$ and exhibited a coefficient of variation (CoV) of $6.2 \%$. With respect to ED_Ref, low welding force and low vibration amplitude were capable of producing ED films of moderate crystallinity, $14.6 \%$ for ED_S and $17.2 \%$ for AMR_ED_S. 


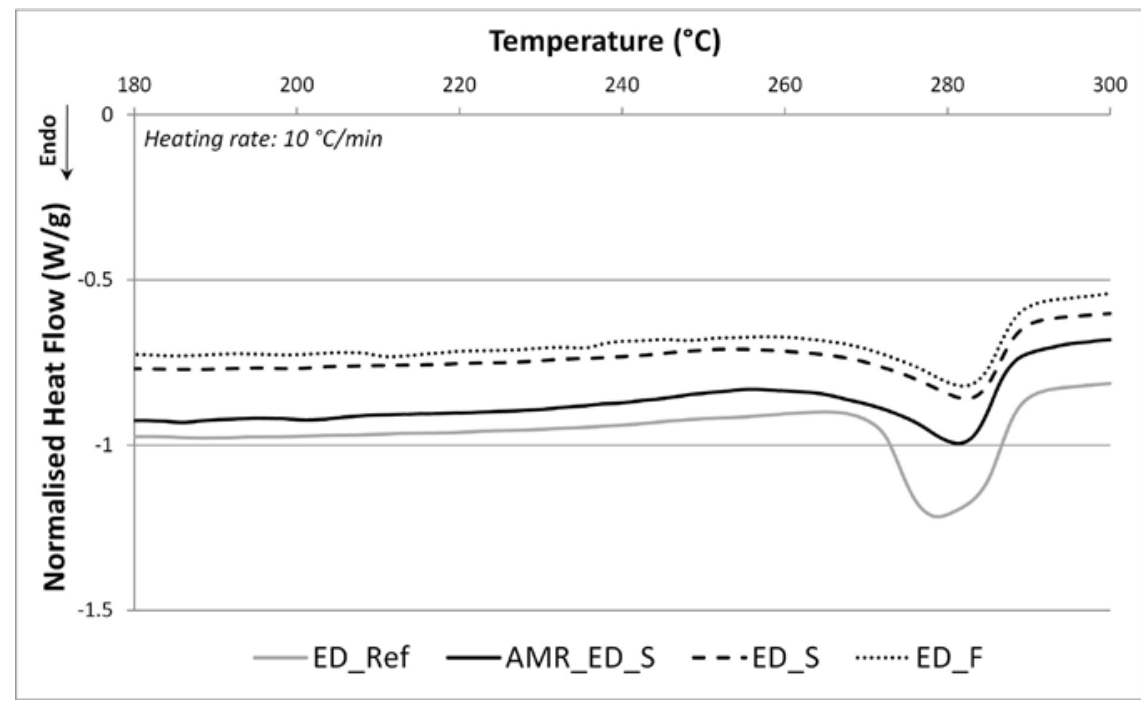

Figure 11. Standard DSC measurements on energy director prior to ultrasonic welding (reference, i.e. after press consolidation and before welding) and on energy directors removed from the welding interface under different welding conditions. The graph focuses on the melting peaks of the four specimens. The curves are vertically shifted for better clarity.

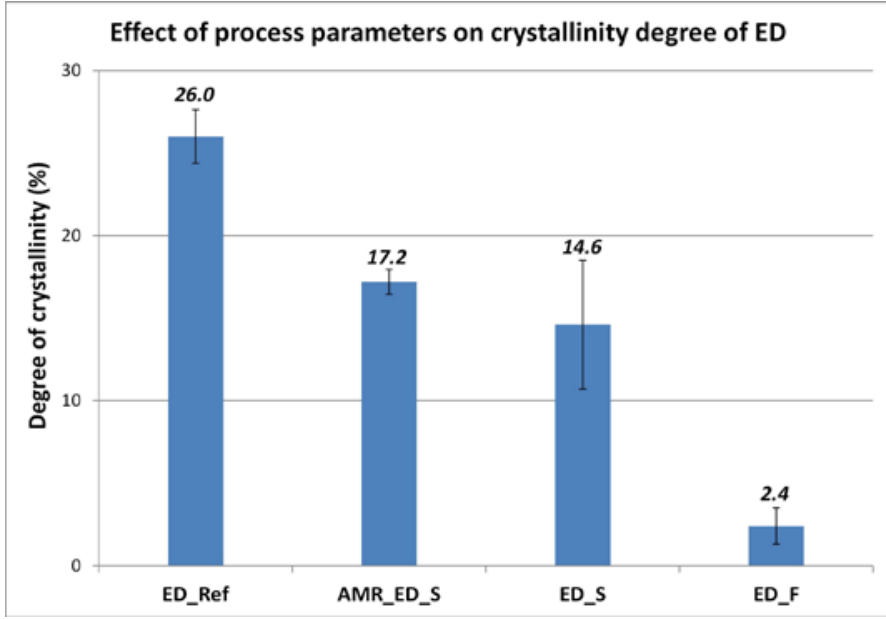

Figure 12. Crystallinity degree of PPS ED films calculated from Standard DSC measurements. Low welding force and low vibration amplitude produced ED films of moderate crystallinity while high welding force and high vibration amplitude produced predominantly amorphous ED films.

On the contrary, high welding force and high vibration amplitude produced a predominantly amorphous PPS, showing a crystallinity degree of only $2.4 \%$. An additional point to be made for Figure 12 is the large scatter of crystallinity degree of ED_S and ED_F, showing CoV equal to $26.7 \%$ and $45.8 \%$, respectively. The large experimental error on the crystallinity values could probably be a result of non-uniform crystallization of the ED films during cooling, however, this was not in line with 
the low experimental error of AMR_ED_S (CoV equal to $4.4 \%$ ). Figure 13 demonstrates the diffraction patterns of four specimens. The intensity of each curve was normalised with respect to the corresponding intensity of the major diffraction peak, $(200,111)$, and plotted against the diffraction

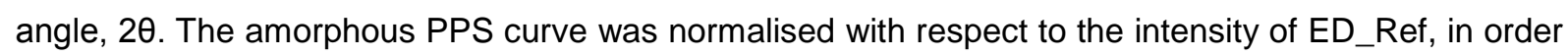
to obtain a clear and readable diffractogram. It can be seen that ED_Ref exhibited narrower diffraction peaks compared to the removed EDs, with ED_F showing the most considerable peak broadening. The latter showed two less distinct peaks within the $2 \theta$ range of $22^{\circ}$ to $25^{\circ}$ and one broad peak within the $2 \theta$ range of $28^{\circ}$ to $34^{\circ}$, compared to the ED_Ref and ED_S which showed four distinct diffraction peaks within the $2 \theta$ range of $28^{\circ}$ to $34^{\circ}$.

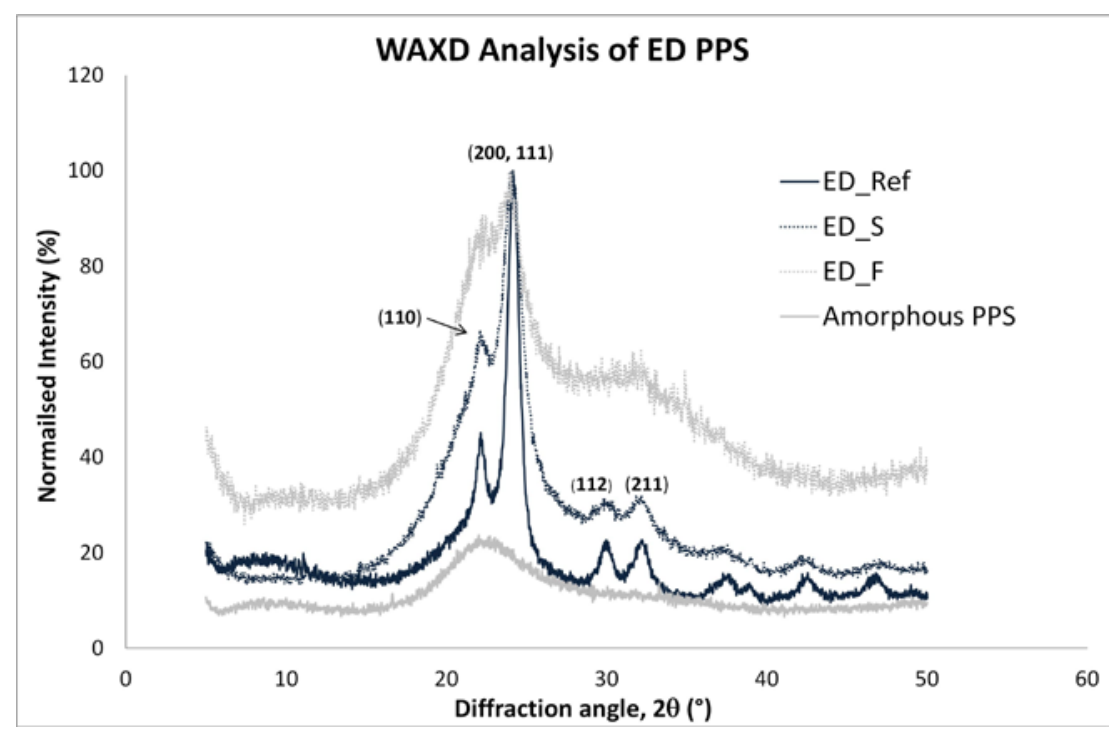

Figure 13. WAXD diffraction patterns showing the effect of the welding process parameters. The intensity of the ED films was normalised with respect to the intensity of the main diffraction peak $(200,111)$.

The amorphous PPS material exhibited a broad peak at $22^{\circ}$, characteristic of the diffraction peak of an amorphous material. Equation (3) was used to estimate the order of magnitude of the average crystallite size of the crystalline phase of PPS, and it was found that the average crystallite sizes of ED_Ref, ED_S and ED_F were $115.6 \AA, 41.3 \AA$ and $25.6 \AA$, respectively. In addition, the positions of the four main PPS diffraction peaks were identified and labelled in the graph [48], and were found to not be influenced by the welding conditions, remaining the same for all specimens. 


\section{Discussion}

In this section, first, a brief analysis of the most probable mechanism responsible for the temperature profile at the centre of the joint overlap is presented, followed by the discussion concerning the influence of the ultrasonic welding parameters on the degree of crystallinity of PPS at the welding interface. Furthermore, the additional features of the thermograms and the WAXD diffractogram of sections 3.1 and 3.2 are addressed.

The temperature profile of ED PPS during the ultrasonic welding process in Figure 6 showed that lowering the welding force and the vibration amplitude decreased the cooling rates significantly. The reasons for the slower cooling rates of ETC_S can be found, mainly, in the slower heat generation, $\dot{Q}$, due to the lower vibration amplitude [6] [7] which is given in the equation:

$Q=\omega^{*} \varepsilon^{2 \star} E^{\prime \prime} / 2$

Where $\varepsilon$ is the strain amplitude, $\omega$ is the frequency and $E^{\prime \prime}$ is the loss modulus. Due to the high thermal conductivity of carbon fibres, heat dissipation occurs, through the composite substrates, increasing their temperature as well. As a result, the slower heat generation would, possibly, cause a larger heat affected zone within the substrates and, essentially, cause a less effective heat transfer leading to a slower cooling of the welding interface. Regarding the relatively large experimental errors of the cooling rates, one possible reason could be the low sampling rate (1 measurement point per $100 \mathrm{~ms})$. Especially for the ETC_F specimens the experimental error was larger since there were less measurement points.

The standard DSC measurements on the removed EDs showed that the process parameters had a substantial impact on the crystallinity degree. Welding using a force of $300 \mathrm{~N}$ and a vibration amplitude of $51.8 \mu \mathrm{m}$ yielded PPS of moderate crystallinity at the welding interface while a welding force of 1000 $\mathrm{N}$ and a vibration amplitude of $86.2 \mu \mathrm{m}$ resulted in predominantly amorphous PPS (Figure 12). Although the DSC measurements are sensitive to chain reorganisation during heating, it is not expected that it would have such a significant impact on the measured crystallinity degree of ED_S and AMR_ED_S, that would result in such a large difference with the crystallinity degree of ED_F. This 
statement is supported by the enthalpy associated to the cold crystallization peaks of the three series presented in Figure 10: this enthalpy for ED_F was much larger than the corresponding areas of ED_S and AMR_ED_S, indicating that a higher crystallinity degree was obtained during cooling using low welding force and low vibration amplitude. Similarly, the lower value of the specific heat capacity of ED_S associated to glass transition (about $41 \%$ lower than that of ED_F) suggests a higher crystallinity degree: the lower $\Delta \mathrm{Cp}$ value is a result of a constrained chain mobility due to the presence of crystals and a smaller amorphous phase content of ED_S. The DSC analysis was complemented by the WAXD analysis which showed that the diffraction pattern of ED_F was different than the diffraction pattern of fully amorphous PPS (Figure 13) while the relatively well-defined diffraction peaks of ED_S confirm the presence of a PPS crystalline phase in specimens welded under low welding force and low vibration amplitude. ED_F showed two very broad diffraction peaks, suggesting lower crystal perfection and lower crystallinity degree than ED_S. With respect to the average crystallite size of PPS, it was found that the very high cooling rates of the USW process caused a reduction in the average crystallite size of PPS. Further evidence supporting the notion of less perfect crystals can also be found in Figure 7 where it is shown that increasing cooling rates resulted in broader melting peaks, which were also shifted to lower temperatures. The appearance of broader melting peaks is an indication of a wider distribution of lamella thickness [50], while it is well known that, under fast cooling, less perfect and/or smaller crystals are being formed at lower melt-crystallization temperatures which, in turn, result in lower melting temperatures [19].

As it was mentioned in section 3.1, the time-temperature relationship was non-linear, however, by dividing the temperature region between the equilibrium melting temperature and $160^{\circ} \mathrm{C}$ into smaller temperature regions, it was demonstrated that the cooling rates of all series, independently of welding force and vibration amplitude, were approximately $11^{\circ} \mathrm{C} / \mathrm{s}$ or higher. Figure 8 showed that increasing cooling rates resulted in lower crystallinity degree values. The polymer chains need time to disentangle from the melt and organise themselves to form crystalline domains, therefore, a fast cooling rate will result in a lower crystallinity degree. Cooling rates of $10{ }^{\circ} \mathrm{C} / \mathrm{s}$ and $20^{\circ} \mathrm{C} / \mathrm{s}$ resulted in crystallinity degrees of only $3.6 \%$ and $0.5 \%$, respectively. The results of the FSC measurements, in conjunction with the measured cooling rates from the temperature measurements, suggest that PPS at the welding interface should be predominantly amorphous regardless of the welding parameters. 
However, the standard DSC and WAXD measurements were not in line with the FSC measurements, as Figure 12 and Figure 13 illustrated. A few potential factors responsible for the disagreement between figure 8 and figure 12 (and figure 13) are critically discussed in the following paragraphs.

\section{Effect of temperature measurements}

As it was mentioned in section 2.3, the EDs used to obtain the temperature profile at the welding interface were thicker than the EDs removed from the welding interface. However, considering the lower cyclic strains that occur in thicker EDs due to their higher stiffness [3], it is expected that the thinnest EDs (i.e. the EDs removed from the welding interface) should exhibit, if not the same, even faster heating and cooling rates. Therefore, it is safe to assume that the higher thickness of ETC_S and ETC_F did not render the measured cooling rates higher than the rates encountered in ED_S and ED_F. With respect to the effect of the sampling rate (1 measurement recorded per $100 \mathrm{~ms}$ ) on the measurement precision, most certainly some temperature values were not recorded, especially during heating, and during cooling from very high temperatures (e.g. from $400{ }^{\circ} \mathrm{C}$ to $300{ }^{\circ} \mathrm{C}$ ). However, at the temperature range between $190{ }^{\circ} \mathrm{C}$ and $160{ }^{\circ} \mathrm{C}$ the rates had decreased significantly (less than 20 ${ }^{\circ} \mathrm{C} / \mathrm{s}$ ), allowing for sufficient measurement points to be recorded (at least 5 points per $10{ }^{\circ} \mathrm{C}$ ) and to calculate the cooling rates in good approximation.

\section{Effect of Kapton films}

One possible reason for this disagreement could be the use of Kapton films in obtaining the ED_S and ED_F specimens, from which the DSC and WAXD measurements were acquired. In particular, the removed EDs were not fully representative of an ED of a consolidated welded joint produced without the interference of Kapton films. Normally, the ED is in contact with the CF/PPS substrates while in our approach, the ED was in contact with the Kapton films which could, potentially, cause different heating and cooling. Kapton_ETC_S exhibited a lower cooling rate than ETC_S, $10.9^{\circ} \mathrm{C} / \mathrm{s}$ compared to 16.9 ${ }^{\circ} \mathrm{C} / \mathrm{s}$, respectively. The differences in the cooling rates between ETC_S and Kapton_ETC_S could be attributed to the thermal insulation properties of Kapton and to the differences in friction between the Kapton - ED interface and CF/PPS - ED interface. On these grounds, it can be argued that the presence of Kapton films altered the heat generation and heat transfer at the overlap, nonetheless, 
$10.9^{\circ} \mathrm{C} / \mathrm{s}$ is still a very high cooling rate and incapable of producing PPS of moderate crystallinity (as a reminder, a cooling rate of $10^{\circ} \mathrm{C} / \mathrm{s}$ resulted in a crystallinity degree of $3.6 \%$ ).

\section{Annealing effect}

It is well known that annealing of semi-crystalline thermoplastics (i.e. heating above $\mathrm{Tg}$ ) leads to increased crystallinity degree and crystal perfection [51]. The changes in the crystalline regions can already occur in the first few minutes of annealing. In addition, the highest the annealing temperature, the shortest the annealing time required. Cold crystallization of PPS occurs around $120-130{ }^{\circ} \mathrm{C}$ which is usually the lowest annealing temperature of PPS; below that temperature the chain mobility is too low and it would require lengthy annealing times to achieve changes in crystallinity and crystal perfection. ETC_F was quenched down to $120{ }^{\circ} \mathrm{C}$ (in almost 2 seconds) while ETC_S and Kapton_ETC_S cooled down slower, in 10.3 and 11.4 seconds, respectively. Hence, an annealing effect could be possible, enhancing the crystallinity degree of ED_S and contributing to the growth of the average crystallite size. However, the studies reporting the effect of annealing on PPS, have investigated times in the order of a few minutes [51] [52]. Performing experiments to isolate the effect of annealing in non-isothermal conditions for such short times is extremely complex and technically challenging. Recognising the absence of experimental proof due to technical complexities, we suggest that annealing had a negligible effect on the crystallinity degree of ED_S due to the very short "annealing" time.

\section{Crystal seed effect}

Another possible reason for the semi-crystalline structure of ED_S could be the presence of remnant crystals in the melt. Although the temperature reached values much higher than the melting temperature of PPS (Figure 6), which ensured that the temperature was high enough to melt the crystals, the material remained a very short time in the melt, which could have caused PPS to partially maintain its chain conformation. Hence, there is always a possibility that some of the crystals, which pre-existed in the initial state of the ED (as received from press consolidation), did not melt or melted partially and, therefore, acted as nucleation sites during cooling (crystal seed effect). However, AMR_ED_S had a crystallinity degree of $17.2 \%$, hence, if the remnant crystals were the main reason 
for the fast crystallization of PPS then AMR_ED_S should have had a much lower crystallinity degree (as the PPS energy director was amorphous in its initial state). Therefore, the (potential) presence of remnant crystals is not considered to have had a major impact on the crystallization of PPS at the welding interface.

\section{Strain-induced crystallization}

One major difference between the crystallization of PPS during FSC tests and during ultrasonic welding is that the former proceeds in quiescent conditions while the latter encounters very high strain rates. The vibration frequency used in the ultrasonic welding process was $20 \mathrm{kHz}$, therefore, very high strain rates could be achieved instantaneously. When a polymer is in the melt state, the molecular chains are entangled and interpenetrated, having a random coil conformation. In quiescent conditions, the crystallization is only driven by chain mobility and supercooling level. If the kinetics of cooling is higher than the crystallization one, crystallization is prevented, leading to an amorphous PPS solid. However, under high strain the molecular chains can be oriented. The formation of nuclei is favoured which, in conjunction with the increase of nucleation density, accelerate crystallization [52], considering the same cooling conditions as in quiescent conditions. The effect of high strain rates on polymer crystallization has also been reported by several researchers [52] - [55], reinforcing our suggestion that strain-induced crystallization could explain the crystallization of PPS despite the very fast cooling rates. Nonetheless, the strain rates are linked to the time available for the molecular chains to form crystals. Although ED_F encountered higher strain rates than ED_S (and AMR_ED_S) due to the higher vibration amplitude $(86.2 \mu \mathrm{m}$ vs $51.8 \mu \mathrm{m})$, PPS in ED_F was almost amorphous, exhibiting a very low degree of crystallinity (2.4\%). A plausible explanation could be the shorter time of melted PPS under high strain rates for ED_F. The crystallization rate of a polymer can be accelerated due to high strain rates, however, it is likely that a very short time in the melt is not sufficient for strain-induced crystallization to occur [52]; for a melted polymer, a given time under high strain rates is required to observe an effect on crystallization kinetics. Zhang et al [55] also suggested that the crystallization rate of PPS increased with increasing shear time. Therefore, it appears that the time under high strain rates for melted PPS in ED_F was not long enough to significantly increase the crystallization rate, while the low welding force and the low vibration amplitude favoured the conditions for strain-induced crystallization to occur by decreasing the cooling rates and allowing more time in the 
melt.

\section{Conclusions}

This article presented an investigation of the crystallinity at the interface of ultrasonically welded CF/PPS joints by studying the influence of welding force and vibration amplitude on the degree of crystallinity at the welding interface. The results of our work can be summarised in the following conclusions:

- Temperature measurements at the centre of the overlap of ultrasonically welded CF/PPS joints revealed that low welding force $(300 \mathrm{~N})$ and low vibration amplitude $(51.8 \mu \mathrm{m})$ decreased the cooling rates from $41^{\circ} \mathrm{C} / \mathrm{s}$ to $16.9^{\circ} \mathrm{C} / \mathrm{s}$, compared to high welding force (1000 $\mathrm{N})$ and high vibration amplitude $(86.2 \mu \mathrm{m})$. The lower cooling rates were attributed to the slower heat generation under $300 \mathrm{~N}$ and $51.8 \mu \mathrm{m}$. It is suggested that the slower heat generation possibly caused a larger heat affected zone, resulting in a less effective heat transfer.

- The FSC experiments showed that the degree of crystallinity of PPS decreased with increasing cooling rates. Furthermore, it was shown that, in quiescent conditions, the critical cooling rate at which PPS crystallization was suppressed was $20^{\circ} \mathrm{C} / \mathrm{s}$, exhibiting a degree of crystallinity of only $0.5 \%$.

- DSC and WAXD measurements performed on energy director films that were removed from the welding interface, showed that the ultrasonic welding process parameters had a significant impact on the crystallinity degree of PPS and its crystal perfection. High welding force (1000 $\mathrm{N})$ and high vibration amplitude $(86.2 \mu \mathrm{m})$ produced predominantly amorphous PPS and imperfect crystals, while low welding force $(300 \mathrm{~N})$ and low vibration amplitude (51.8 $\mu \mathrm{m})$ were capable of increasing the crystallinity to moderate levels as well as the crystal perfection. Although the crystallinity degree and the crystal perfection were not as high as in the initial state of the PPS energy directors (i.e. prior to ultrasonic welding), it was clear from the DSC thermograms and the WAXD diffractogram that PPS had obtained a semi-crystalline structure. 
A possible explanation for the PPS capability to crystallise despite the very high cooling rates at the centre of the overlap, is the significantly high strain rates involved in the ultrasonic welding process which are suggested to have induced PPS crystallization. The orientation of the molecular chains in the melt due to high strain rates could have facilitated crystal formation and accelerated PPS crystallization. Hence, it was shown that by appropriately modifying the welding force and the vibration amplitude it was possible to obtain a semi-crystalline welding interface.

\section{Acknowledgements}

This study is part of the Thermoplastic Affordable Primary Aircraft Structure 2 (TAPAS2) project, financed by Netherlands Enterprise Agency of the Ministry of Economic Affairs. The authors gratefully acknowledge Ben Norder for his technical assistance and for performing the XRD experiments.

\section{References}

[1] Villegas IF. Strength development versus process data in ultrasonic welding of thermoplastic composites with flat energy directors and its application to the definition of optimum processing parameters. Composites: Part A 2014; 65: 27-37.

[2] Villegas IF. In situ monitoring of ultrasonic welding of thermoplastic composites through power and displacement data. J Thermoplast Compos Mater 2015; 28: 66-85.

[3] Palardy G, Villegas IF. On the effect of flat energy directors thickness on heat generation during ultrasonic welding of thermoplastic composites. Comp Interfaces 2017; 24:2, 203-214.

[4] Potente H. Ultrasonic welding - principles and theory. Mater De 1984; 5(5): 228-34.

[5] Benatar A, Gutowski TG. Ultrasonic welding of PEEK graphite APC-2 composites. Polym Eng Sic 1989; 29(23): 1705-21.

[6] Tolunay MN, Dawson PR, Wang KK. Heating and bonding mechanisms in ultrasonic welding of thermoplastics. Polym Eng Sci 1983; 23(13): 726-33. 
[7] Levy A, Le Corre S, Villegas IF. Modeling of the heating phenomena in ultrasonic welding of thermoplastic composites with flat energy directors. J Mater Process Technol 2014; 214: $1361-1371$

[8] Liu SJ, Chang IT. Optimizing the weld strength of ultrasonically welded nylon composites. J. Compos Mater 2002; 36: 611-624.

[9] Liu Sj, Chang IT, Hung SW. Factors affecting the joint strength of ultrasonically welded polypropylene composites. Polymer Composites 2001; 22(1): 132-141.

[10] Benatar A, Eswaran RV, Nayar SK. Ultrasonic Welding of thermoplastics in the near-field. Polymer Engineering and Science 1989; 29(23): 1689-1698.

[11] Barroso M, Villegas IF, Bersee HEN. Optimizing ultrasonic welding of carbon-fibre reinforced polyetherimide. JEC Mag 2012; 70: 54-58.

[12] Brady DG. The crystallinity of poly(phenylene sulfide) and its effect on polymer properties. Journal of Applied Polymer Science 1976; 20: 2541-2551.

[13] Kenny JM, Maffezzoli A. Crystallization kinetics of poly(phenyene sulfide) (PPS) and PPS/Carbon Fiber Composites. Polym Eng Sci 1991; 31(8): 607-614.

[14] Maffezzoli A, Kenny JM, Nicolais L. A macrokinetic approach to crystallization modelling of semicrystalline thermoplastic matrices for advanced composites. J. Mat. Sci 1993; 28 (18): 4994-5001.

[15] Gao SL, Kim JK. Cooling rate influences in carbon fibre/PEEK composites. Part 1. Crystallinity and interface adhesion. Composites: Part A 2000; 31: 517-530.

[16] Talbott MF, Springer GS, Berglund LA. The effects of crystallinity on the mechanical properties of PEEK polymer and graphite fiber reinforced PEEK. J Comp Mater 1987; 21: $1056-1081$.

[17] Grouve WJB, Vanden Poel G, Warnet LL, Akkerman R. On crystallization and fracture toughness of poly(phenylene sulphide) under tape placement conditions. Plastics, Rubber and Composites 2013; 42(7): 282-288.

[18] Furushima Y, Kumazawa S, Umetsu H, Toda A, Zhuravlev E, Schick C. Melting and recrystallization kinetics of poly(butylene terephthalate). Polymer 2017; 109: 307-314.

[19] Chung JS, Cebe P. Melting behaviour of poly(phenylene sulphide): 1. Single-stage melt crystallization. Polymer 1992; 33(11): 2312-2324. 
[20] Ferrara JA, Seferis JC, Sheppard CH. Dual-mechanism kinetics of polyphenylene sulfide (PPS) melt-crystallization. J Thermal Analysis 1994; 42: 467-484.

[21] Tardiff X, Pignon B, Boyard N, Schmelzer JWP, Sobotka V, Delaunay D, Schick C. Experimental study of crystallization of polyetheretherketone (PEEK) over a large temperature range using a nano-calorimeter. Polymer Testing 2014; 36: 10-19.

[22] Schick C, Mathot V. Fast Scanning Calorimetry. Springer, 2016.

[23] Gradys A, Sajkiewicz, Adamovsky S, Minakov A, Schick C. Crystallization of poly(vinylidene fluoride) during ultra-fast cooling. Thermochim Acta 2007; 461: 153-157.

[24] Zhuravlev E, Madhavi V, Lustiger A, Androsch R, Schick C. Crystallization of polyethylene at large undercooling. ACS Macro Lett 2016; 5: 365-370.

[25] Gradys A, Sajkiewicz P, Zhuravlev E, Schick C. Kinetics of isothermal and non-isothermal crystallization of poly(vinylidene fluoride) by fast scanning calorimetry. Polymer 2016; 82: 4048.

[26] Toda A, Androsch R, Schick C. Insights into polymer crystallization and melting from fast scanning chip calorimetry. Polymer 2016; 91: 239-263.

[27] Schawe JEK. Influence of processing conditions on polymer crystallization measured by fast scanning DSC. J Therm Analysis Calorimetry 2014; 116: 1165-1173.

[28] Furushima Y, Nakada M, Yoshida Y, Okada K. Crystallization/melting kinetics and morphological analysis of polyphenylene sulfide. Macro Chem Phys 2018; 219(2): 1700481.

[29] Furushima Y, Schick C, Toda A. Crystallization, recrystallization, and melting of polymer crystals on heating and cooling examined with fast scanning calorimetry. Polymer Crystallization 2018; 1: e1005.

[30] Velisaris CN, Seferis JC. Crystallization kinetics of polyetheretherketone (PEEK) matrices. Polym Eng Sci 1986; 26(22): 1574-1581.

[31] Spruiell JE, Janke CJ. A review on the measurement and development of crystallinity and its relation to properties in neat poly(phenylene sulfide) and its fiber reinforced composites. Technical Report, Oak Ridge National Laboratory, 2004.

[32] Schulz E, Kalinka G, Auersch W. Effect of transcrystallization in carbon fiber reinforecd poly(p-phenylene sulfide) composites on the interfacial shear strength investigated with the single fiber pull-out test. J Macromol Sci Part B 1996; 35(3-4): 527-546. 
[33] Gao SL, Kim JK. Cooling rate influences in carbon fibre/PEEK composites. Part II: interlaminar fracture toughness. Composites: Part A 2001; 32: 763-774.

[34] Sacchetti F, Grouve WJB, Warnet LL, Villegas IF. Effect of cooling rate on the interlaminar fracture toughness of unidirectional carbon/PPS laminates. Eng Fract Mech 2018; 203: 126136.

[35] Karger-Kocsis J, Friedrich K. Temperature and strain-rate effects on the fracture toughness of poly(ether ether ketone) and its short glass-fibre reinforced composite. Polymer 1986; 27 : 1753-1760.

[36] Grouve WJB, Warnet LL, Rietman B, Akkerman R. On the weld strength of in situ placed reinforcements on weave reinforced structures. Composites: Part A 2012; 43: 1530-1536.

[37] Stober EJ, Seferis JC. Fluid sorption characterization of PEEK matrices and composites. Polym Eng Sci 1988; 28(9): 634-639.

[38] Stober EJ, Seferis JC, Keenan JD. Characterization and exposure of polyetheretherketone (PEEK) to fluid environments. Polymer 1984; 25: 1845-1852.

[39] Ma CCM, Lee CL, Tai NH. Chemical resistance of carbon fiber reinforced poly(ether ether ketone) and poly(phenylene sulfide) composites. Polym Comp 1992; 13(6): 435-440.

[40] Ma CCM, Lee CL, Chang MJ, Tai NH. Hygrothermal behaviour of carbon fiber reinforced poly(ether ether ketone) and poly(phenylene sulfide) composites. I. Polym Comp 1992; 13(6): 448-453.

[41] Wolf C, Flu H. Stress-enhanced transport of toluene in poly aryl ether ether ketone (PEEK). J Polym Sci: Part B: Polym Phys 1996; 34: 75-82.

[42] Sperling LH. Introduction to physical polymer science. Pennsylvania: Wiley-Interscience, 1986.

[43] Hu W. Polymer physics: A molecular approach. Cambridge: Spinger, 2012.

[44] Chung JS, Cebe P. Crystallization and melting of cold-crystallized poly(phenylene sulfide). J Polym Sci: Part B: Polym Phys 1992; 30: 163-176.

[45] Huo P. Cebe P. Effects of thermal history on the rigid amorphous phase in poly(phenylene sulfide). Colloid Polym Sci 1992; 270: 840-852. 
[46] Qazi SJS, Rennie AR, Cockcroft JK, Vickers M. Use of wide-angle X-ray diffraction to measure shape and size of dispersed colloidal particles. J Colloid Interface Science 2009; 338: $105-110$.

[47] Wu D, Zhou C, Fan X, Mao D, Bian Z. Morphology, crystalline structure and isothermal crystallization kinetics of polybutylene terephthalate/montmorillonite nanocomposites. Polymer \& Polymer Composites 2005; 13(1): 61-71.

[48] Lee TH, Boey FYC, Khor KA. X-Ray diffraction analysis technique for determining the polymer crystallinity in a polyphenylene sulfide composite. Polym Comp 1995; 16(6): 481-488.

[49] Borchert H. Shevchenko EV, Robert A, Mekis I, Kornowski A, Grübel, Weller H. Determination of nanocrystal sizes: A comparison of TEM, SAXS, and XRD studies of highly monodisperse CoPt3 particles. Langmuir 2005; 21: 1931-1936.

[50] Lauritzen Jr JI, Hoffman JD. Extension of theory of growth of chain-folded polymer crystals to large undercoolings. J Appl Phys 1973; 44(10): 4340-4352.

[51] Ostberg GM, Seferis JC. Annealing effects on the crystallinity of polyetheretherketone (PEEK) and its carbon fiber composite. J Appl Polym Sci 1987; 33: 29-39.

[52] Arici A, Sinmazcelik T, Capan L, Yilgor I, Yilgor E. Influence of annealing on the performance of short glass fiber-reinforced polyphenylene sulfide (PPS) composites. J Comp Mat 2005; 39 (1): 21-32.

[53] Chien MC, Weiss RA. Strain-induced crystallization behavior of poly(ether ether ketone) (PEEK). Polym Eng Sci 1988; 28(1): 6-12.

[54] Rao IJ, Rajagopal KR. A study of strain-induced crystallization of polymers. International Journal of Solids and Structures 2001; 38: 1149-1167.

[55] Yoon WJ, Myung HS, Kim BC, Im SS. Effect of shearing on crystallization behavior of poly(ethylene naphthalate). Polymer 2000; 41: 4933-4942.

[56] Zhang RC, Xu Y, Lu A, Cheng K, Huang Y, Li ZM. Shear-induced crystallization of poly(phenylene sulfide). Polymer 2008; 49: 2604-2613. 